\title{
Numerical Simulations of Tap Test on Composite Structures
}

\author{
Sung Joon Kim \\ Korea Aerospace Research Institute, 169-84, Gwahangno, Yuseong-gu, Daejeon, 305-806, Korea.
}

(Received 25 April 2017; accepted 2 February 2018)

The percentage of composite materials used in aircraft construction continues to increase. A particular type of damage such as delamination due to impact can produce significant strength reduction without being visible to the naked eye. The coin tap method is a traditional non-destructive testing method, and it is widely used in composite structure inspection. In this work, the phenomenon of the tapping sound generation is modelled as sound radiation from the vibrating surface due to impact. Arbitrarily supported boundary edges are modelled by elastic restraints, and the effects of boundary condition on tapping sound are discussed. A comparison between the measured and simulated transient acoustic fields generated by an impacted composite plate is reported. The plate vibration is simulated in the time domain using a spring mass model. In this study, the radiated sound induced by impact was computed by solving the Rayleigh integral equation. The spring mass model is also applied to composite sandwich structures to detect disbonding between face sheets and the core.

\section{INTRODUCTION}

The main methods used by aerospace industries to inspect damage are visual inspection and coin tapping. ${ }^{1}$ Visual inspection, which is quick and low cost, is an obvious approach to assess surface damage. A tap test is also an inexpensive inspection technique, which has in recent years been automated for greater accuracy. ${ }^{2}$

A tap test is one of the simplest non-destructive inspection methods which serves as a first line of defense when looking for flaws in composite structures. ${ }^{3}$ Tap test works well for thin laminates, honeycomb structures and other sandwich panels, but it is not so effective on thicker parts. ${ }^{4,5}$ When testing thick composite structures, deeply buried defects are inaudible to human ear. ${ }^{5}$ Tap test only requires a coin (or similar object) and a good sense of hearing. As the surface is impacted with the coin, it emits a sound which is dependent upon the local stiffness. When a tap occurs over a damaged area, where the local stiffness is lower, the sound is dampened, producing a "dead" tone compared to a tap over an undamaged region which produces a higher tone. ${ }^{6}$ With this simple method, operators are able to quickly identify major flaws requiring further inspection of the structure.

The tap test can use two kinds of physical measures such as impact force and acoustic emission. The impact force can be acquired by using a force transducer, and sound pressure is detected via a microphone. The tap test finds flaws only in the exact region of tapping, and it is necessary to tap multiple regions to examine a wider area. The tap test uses the difference between the measured impact force or sound pressure histories of an undamaged structure and a locally damaged structure. For structurally radiated sound, the acoustic field is directly coupled to the structural response.

The finite element method (FEM) used to analyze the impact behavior of the composite laminate has been known to require a long computation time due to the nonlinear nature of the contact condition. For instance, Shivakumar et al. did not use FEM to compute the impact behavior of laminate, but instead used a spring mass model to predict the impact force history. ${ }^{7}$ In their study, the contact energy due to indentation as well as the transverse shear and bending energy of the laminate are considered, and they reported that the contact energy can be neglected in the thin plate. However, their study was confined to circular plates with transversely isotropic properties. Choi suggested a spring mass model using linearized contact law. ${ }^{8,9}$ In that study, it was reported that the linearized contact law approach could be applied to a low-velocity impact response analysis problem by using commercial FEM software. Kim proposed an equivalent mass model to model a hammershaped impactor. From the test results, it was observed that the equivalent mass model provided an appropriate solution when the impactor shape was complex. ${ }^{10}$

Many researchers have investigated the radiated sound from a vibrating structure by using a numerical method. ${ }^{11,12}$ If the acoustic loading is assumed to be negligible and the dynamic behavior of the structure and radiated sound are de-coupled, the radiated sound can be analyzed by using a Rayleigh surface integral. The radiated sound pressure has been compared to tap test data. The tap test serves as a good initial examination to identify major flaws, yet it lacks the sensitivity related to the other effects such as boundary condition. Minak et al. investigated the effect of clamped and simple support boundary conditions on circular carbon fiber reinforced polymer (CFRP) laminates subject to low velocity impact. The results showed that the clamped boundary condition increased the stiffness leading to increase delamination. ${ }^{13}$

Kim investigated the effect of in-plane load on the tap test. ${ }^{10}$ Most aircraft structures are under some degree of load while on the ground. The upper skin of the main wing is subjected to in-plane tensile load, while the lower skin is subjected to compressive load. Therefore, the effect of in-plane loads should be considered when the tap test is performed. From the results of that study, it could be seen that the initial in-plane tensile load increased the stiffness of the laminates. In contrast, the stiffness of the laminates decreased under an in-plane compressive load. Therefore, the contact force and contents of high-frequency sound increase under an in-plane tensile load 


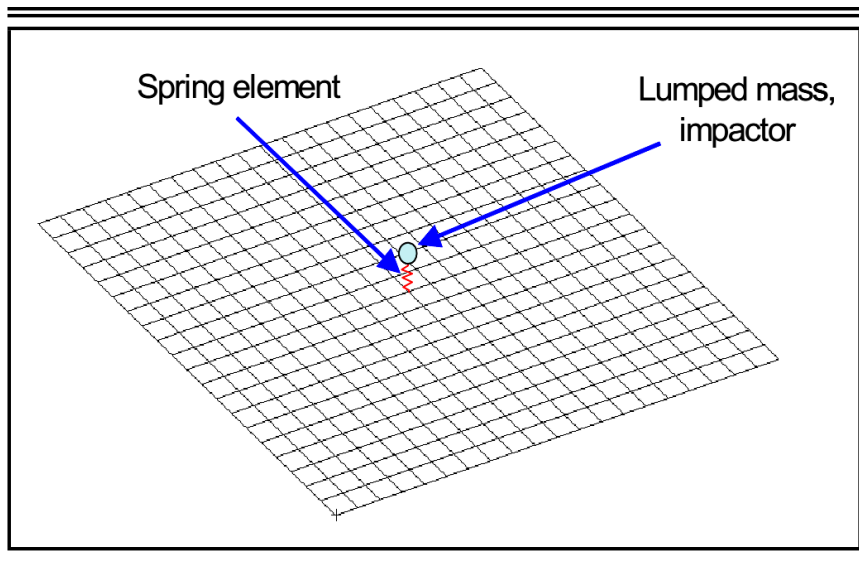

Figure 1. Spring mass model using commercial FEM software.

while the contact force and contents of a high-frequency sound decrease under an in-plane compressive load.

Composite sandwich plates are widely used in the aerospace industry because of their high specific strength and stiffness. However, a composite sandwich exhibits a relatively low impact damage resistance by the low fracture toughness of matrix in the laminate face sheet. The impact damage of a composite sandwich-panel is difficult to detect because of the nature of sandwich structure, and such damage can cause a significant reduction in the load capacity of the composite sandwich. ${ }^{14}$

In this study, a numerical simulation is used to investigate the effect of boundary condition on composite laminates and damage in the sandwich structure. The boundary condition effects are simulated by employing artificial springs to restrain edge displacement and a de-bonding model is used to simulate the damage in the sandwich structure.

\section{NUMERICAL SIMULATION OF TAP TEST}

The tapping event can be regarded as an impact problem. In this paper, the spring mass model was applied to compute the impact behaviour of the composite laminate. If the transverse displacement of an impacted plate is very small, compared to the thickness of the plate, one may consider the plate as a plane source in an infinite baffle. When reflection and diffraction of sound at the boundary of the plate are ignored, the sound pressure radiated from the plate can be obtained from Rayleigh's surface integral. ${ }^{15}$

\subsection{Validation of Numerical Model}

\subsubsection{Impact Response Analysis}

The difference of displacement between the impactor and deformation of laminate at the impacted location means indentation. The indentation is converted to contact force using contact law or experimental indentation law. Choi showed that a linearized contact law approach can be applied to a low-velocity impact response analysis problem with the use of commercial FEM software. ${ }^{9}$ In this paper, MSC/NASTRAN is used. Figure 1 shows the FEM model for impact response analysis. The mass of the impactor is located at the end of the spring element, and the other end of the spring element is attached to the laminate at the impacted location. After impact analysis, we can extract the impact force history acting at the spring. In the FEM model, a four-node plate element was used and transient analysis was carried out with the initial condition

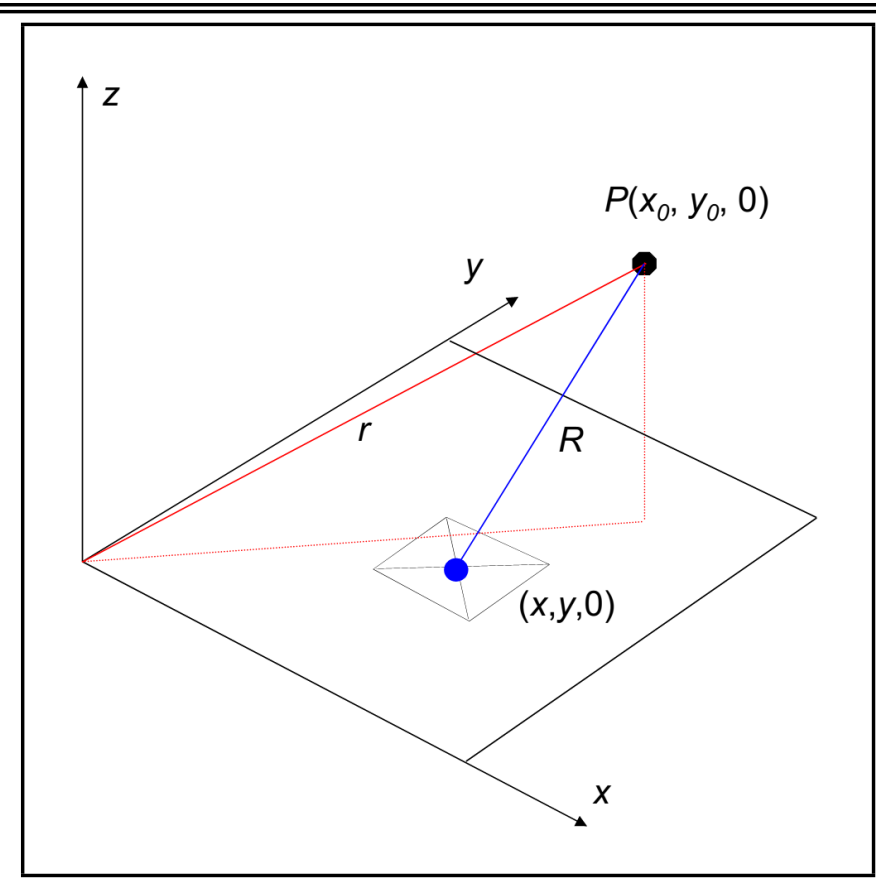

Figure 2. Coordinate system used for evaluating acoustic pressure.

Table 1. Material properties.

\begin{tabular}{|c|l|}
\hline \multirow{5}{*}{ Material properties of lamina } & $E_{1}=132.0 \mathrm{GPa}, E_{2}=8.0 \mathrm{GPa}$ \\
& $G_{12}=G_{13}=G_{23}=3.74 \mathrm{GPa}$ \\
& $\nu_{12}=0.3$ \\
& $\rho=1600.0 \mathrm{~kg} / \mathrm{m}^{3}$ \\
& Thickness $=0.14 \mathrm{~mm}$ \\
\hline \multirow{3}{*}{ Material properties of impactor } & $E=70.0 \mathrm{GPa}$ \\
& $\nu=0.3$ \\
& $\rho=2700.0 \mathrm{~kg} / \mathrm{m}^{3}$ \\
\hline
\end{tabular}

of initial velocity of the lumped mass being given as impact velocity. This spring mass model consists of one spring representing the stiffness of contact law and plate elements representing the composite laminate. The hammer-shaped impactor is simplified by having the concentrated mass use the spring mass model. The equivalent concentrated mass is determined by the following procedure: ${ }^{10}$

$$
m g R_{c} \times(1-\cos \theta)=\frac{1}{2} I_{0} \dot{\theta}^{2} ; \quad v_{i}=\dot{\theta} \times R_{i} ;
$$

where $R_{c}$ is the mass centre of the impactor, $\theta$ is the angle rotated from the neutral position, $I_{0}$ is the mass moment of the inertia of the impactor with respect to rotation centre, $v_{i}$ is the impact velocity of the impact position and $\dot{\theta}$ is the angular velocity of the impactor. The equivalent impactor mass is computed as follows:

$$
\frac{1}{2} I_{0} \dot{\theta}^{2}=\frac{1}{2} m_{e} v_{i}^{2}
$$

where $m_{e}$ is the equivalent mass of the impactor. In this model, model parameters are mass and mass moment of inertia of impactor.

\subsubsection{Acoustic Sound Analysis}

The acoustic sound radiated from a vibrating plate can be obtained by evaluating the Rayleigh surface integral where each elemental area on the plate's surface is regarded as a point source of an outgoing wave and its contribution is summed 


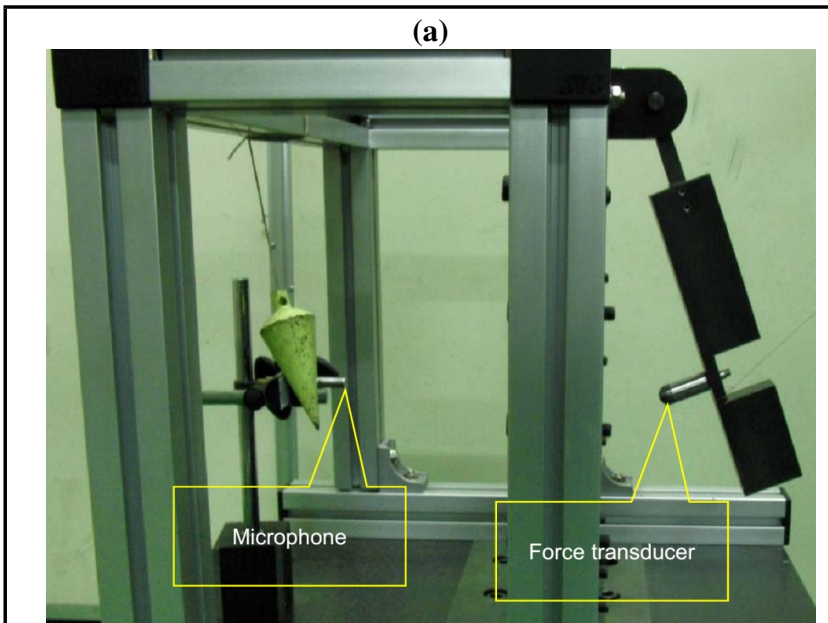

(b)

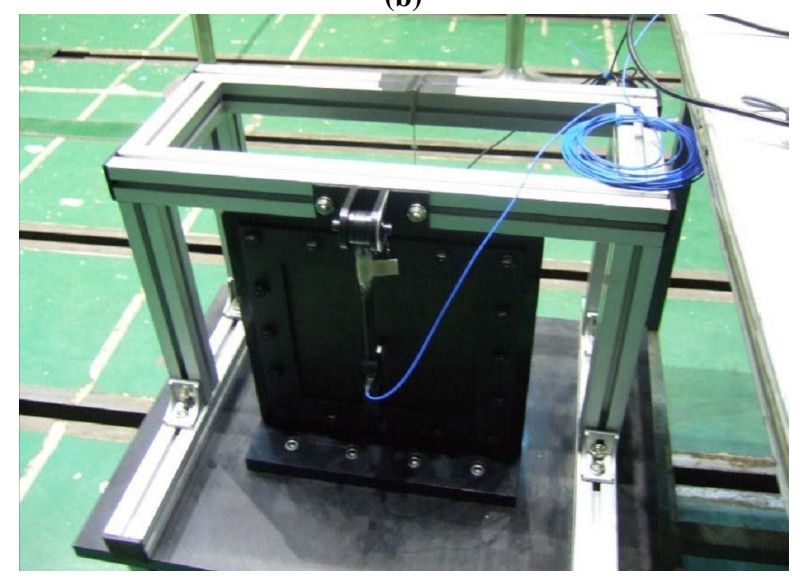

Figure 3. Tap test system: (a) Side view, (b) Front view.

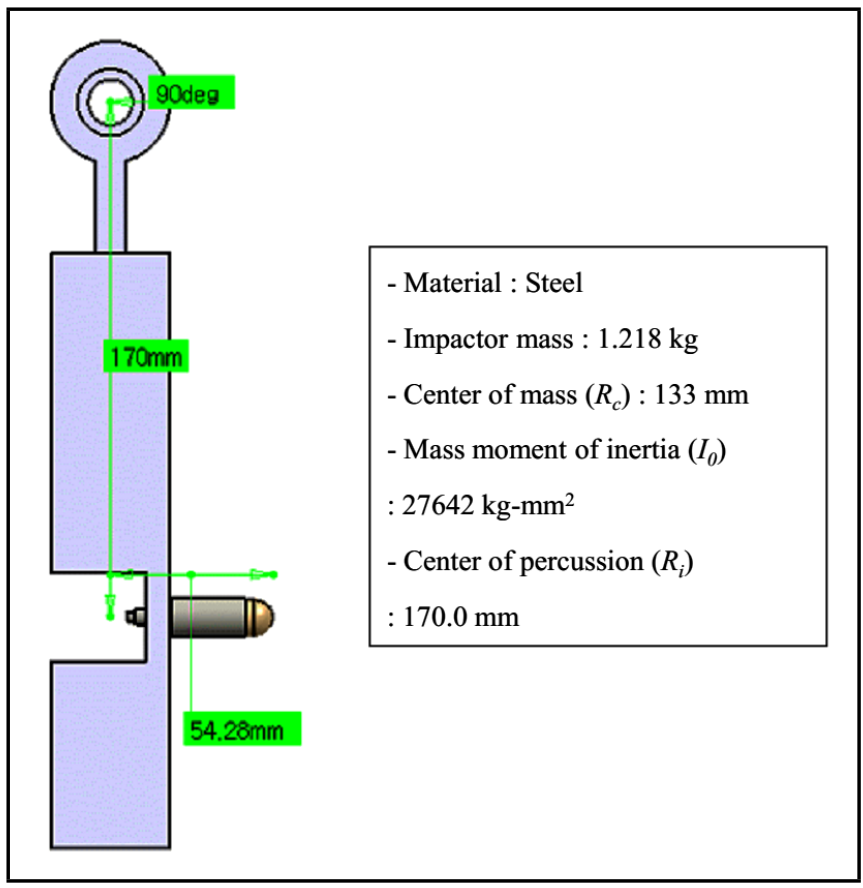

Figure 4. Configuration of impactor.

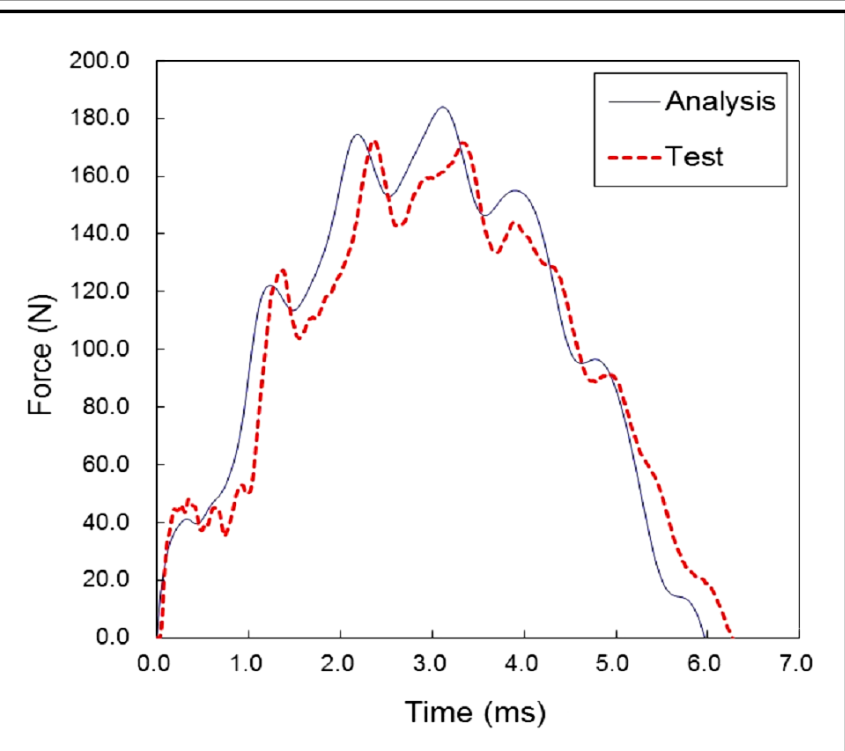

Figure 5. Comparison of impact force between analysis and test.

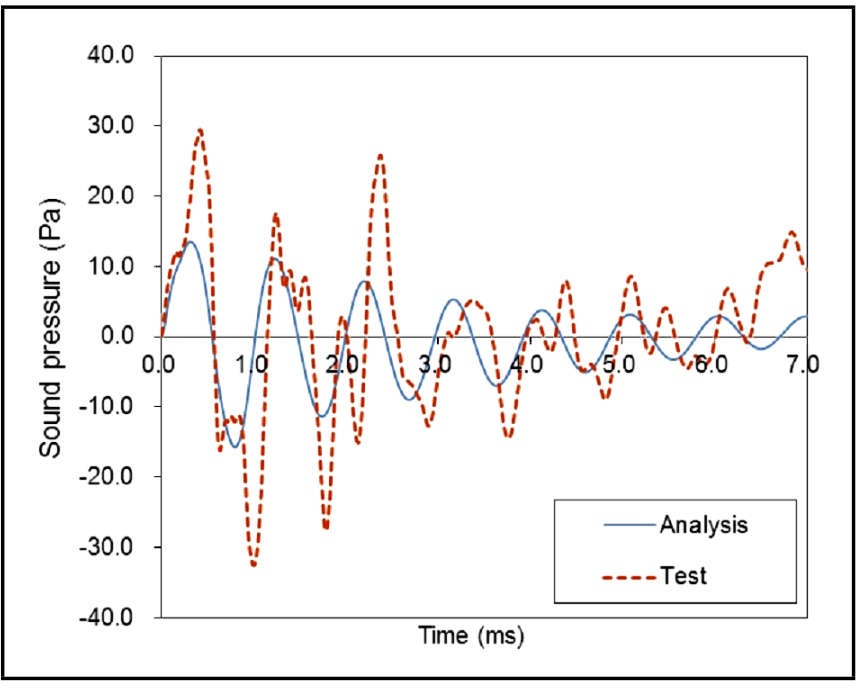

Figure 6. Comparison of sound pressure history between analysis and test.

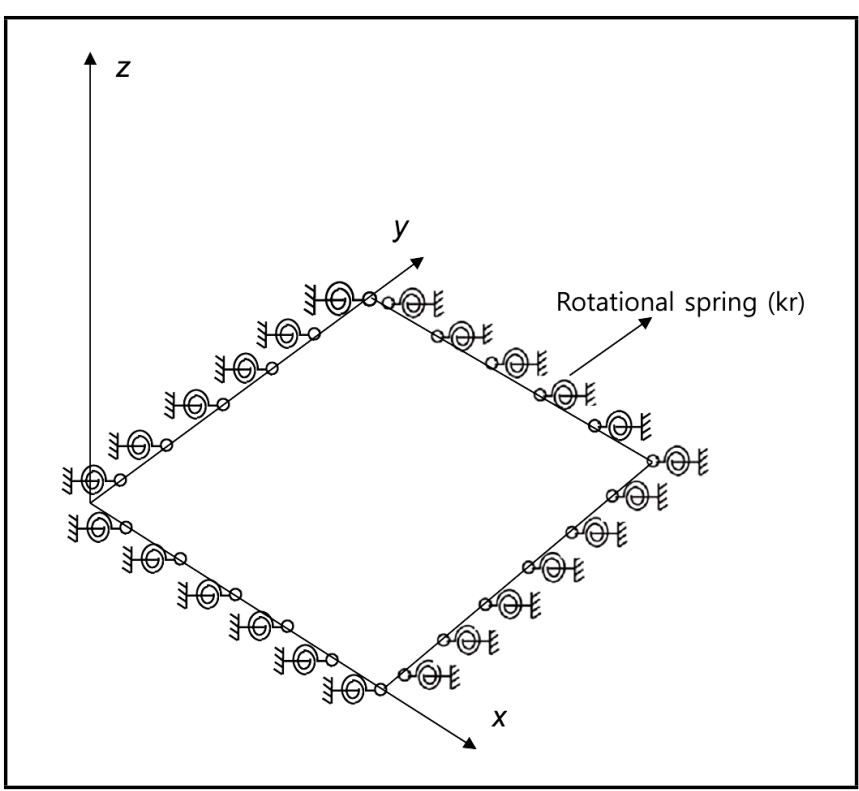

Figure 7. Boundary condition using rotational spring. 


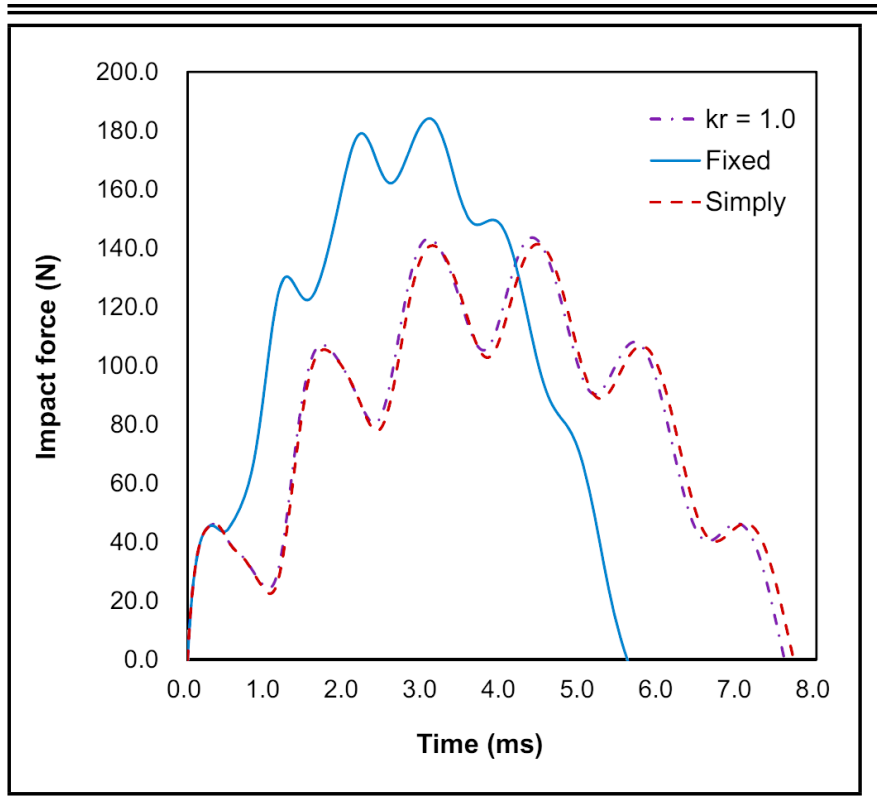

Figure 8. Comparison of impact force history with rotational stiffness $1.0 \mathrm{Nm}$.

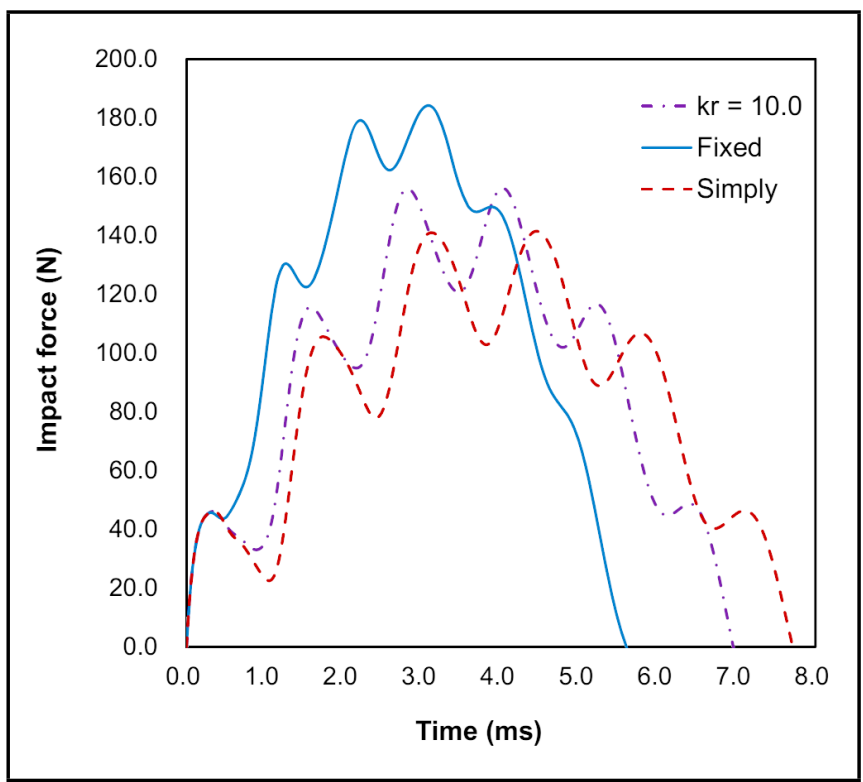

Figure 9. Comparison of impact force history with rotational stiffness $10.0 \mathrm{Nm}$.

with an appropriate time delay. Referring to Fig. 2, the acoustic pressure $P(r, t)$ at observation point $r_{0}$ with a Cartesian coordinate $\left(x_{0}, y_{0}, z_{0}\right)$ at time $t$ induced by the vibration of the plate is analysed by using the Rayleigh surface integral, which is shown in Eq. (3):

$$
P(r, t)=-\frac{\rho_{a}}{2 \pi} \int_{(S)} \frac{1}{\left|r-r_{0}\right|} \frac{\partial^{2}}{\partial t^{2}} W\left(r_{0}, t-\frac{\left|r-r_{0}\right|}{c_{a}}\right) d S .
$$

where $\rho_{a}$ and $c_{a}$ are the mass density and wave velocity of the acoustic medium, $\partial^{2} W / \partial t^{2}$ is the acceleration of the plate element, which was computed from impact response analysis, and applied with an appropriate time delay. The properties of air as the acoustic medium are density $\rho_{a}=1.21 \mathrm{~kg} / \mathrm{m}^{3}$ and speed of sound $c_{a}=340 \mathrm{~m} / \mathrm{s}$.

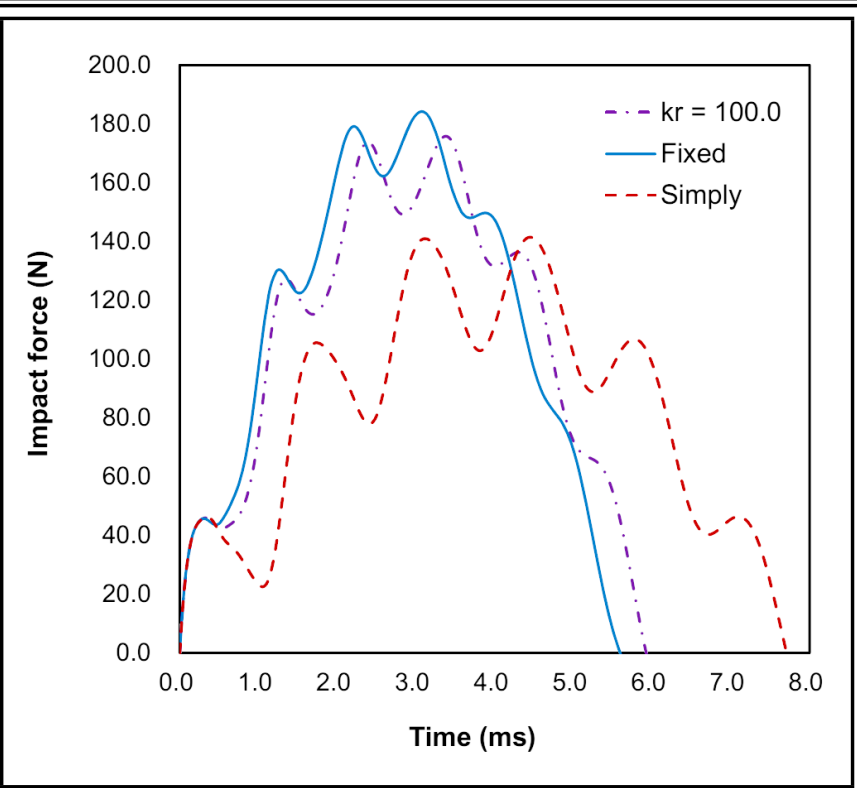

Figure 10. Comparison of impact force history with rotational stiffness $100.0 \mathrm{Nm}$.

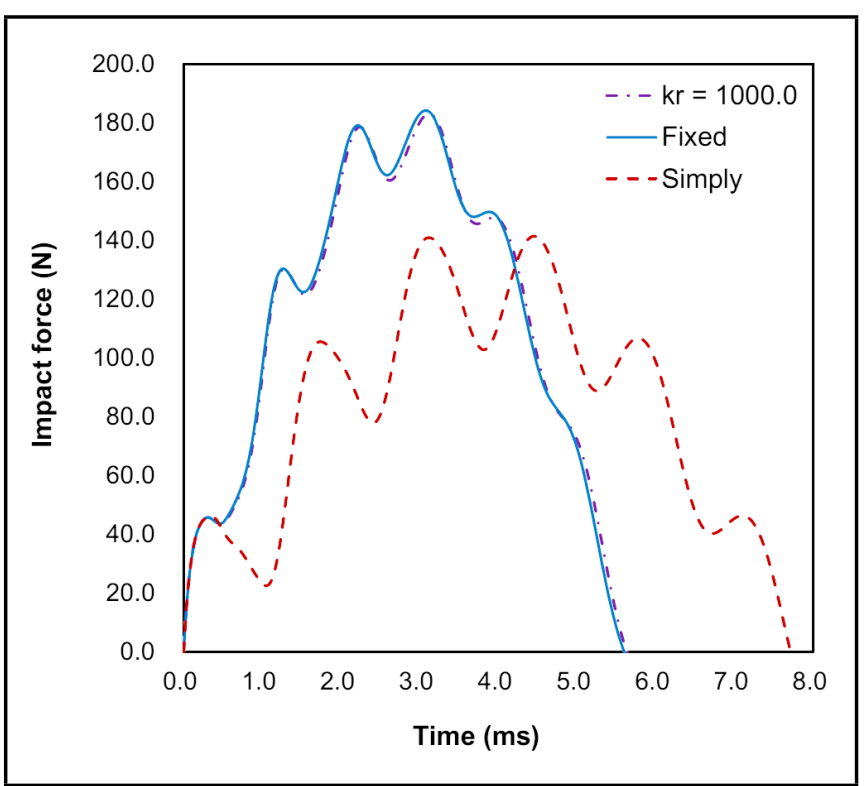

Figure 11. Comparison of impact force history with rotational stiffness $1000.0 \mathrm{Nm}$.

\subsubsection{Validation of Numerical Model}

The experimental investigation was performed on a laminate specimen. The dimension of the laminate was $19 \times 19 \mathrm{~cm}^{2}$, and the boundary condition of the plate had four edges clamped. In this paper, in order to make the fixed boundary condition during contact duration, a bolt clamped device was used to fix the laminate specimen. The laminate had a lay-up of $[0 / 45 / 0 /-45 / 0 /-45 / 0 / 45 / 90]_{\mathrm{s}}$. The material properties of the lamina are shown in Table 1 . A pendulum type tap test system was set up as shown in Fig. 3. A piezoelectric force transducer sensor was used to measure the impact force history. The force transducer was located at the mid position of the impactor. A microphone was used to measure the sound pressure. The microphone was located $15.0 \mathrm{~cm}$ behind the centre of the laminate. Figure 4 shows the shape of the impactors. A tapping event is occurred when an impactor was rotated upward 


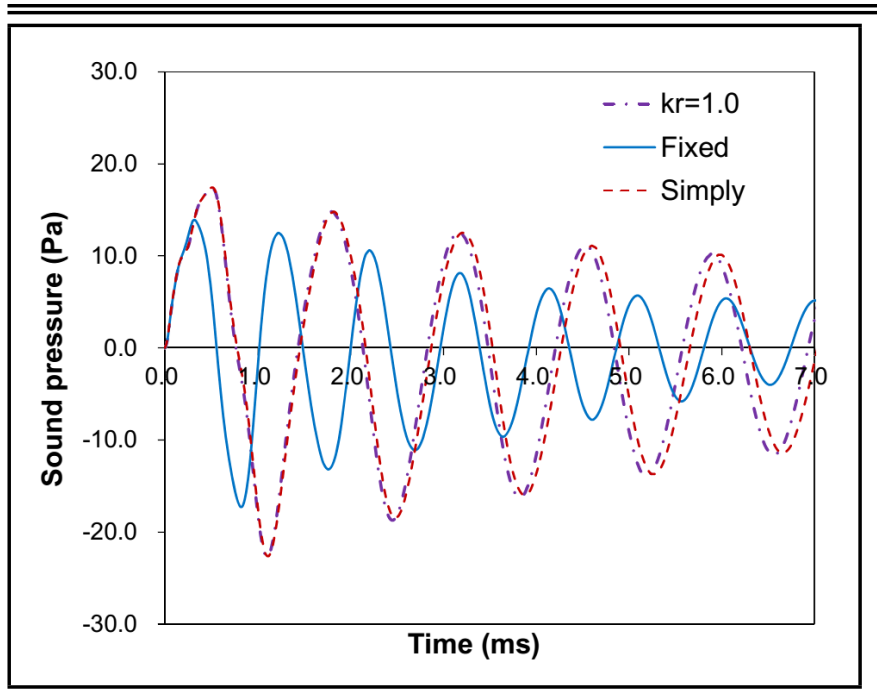

Figure 12. Comparison of sound pressure history with rotational stiffness $1.0 \mathrm{Nm}$.

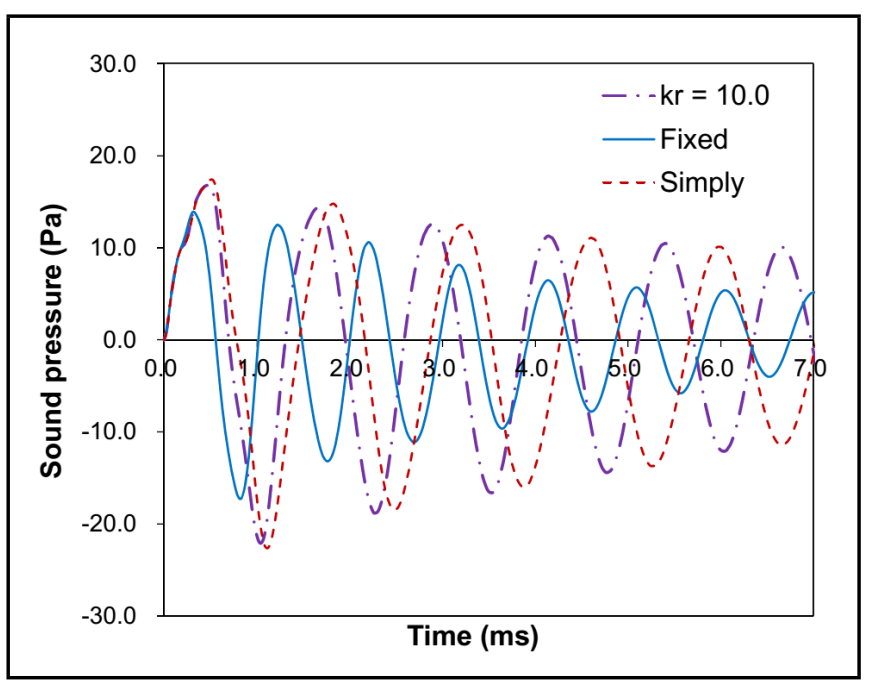

Figure 13. Comparison of sound pressure history with rotational stiffness $10.0 \mathrm{Nm}$.

from the vertical position and then released. Figure 5 shows the impact force history given by the analysis and test when an impactor was rotated 15.0 degrees from the vertical line and then released. In this case, the impact velocity is $0.337 \mathrm{~m} / \mathrm{s}$ and the equivalent mass is $0.956 \mathrm{~kg}$. This figure shows that the impact force history computed by the spring mass model provided accurate results. Figure 6 shows the sound pressure given by the analysis and test. Some differences may have occurred in sound pressure due to possible imperfections of the experimental impact and support conditions. These calculations did not consider the energy from the fixture and the reflection of sound.

\subsection{Influence of Boundary Condition}

In general, composite laminates are used to fabricate structural parts. These products are supported by elastic restraints or connected to other members, which can also be treated as elastic supports for restraining the plates. Therefore, the effect of an elastically restrained boundary should be considered when the tap test is performed. To predict the effect of support properties on the sound radiated from the plate and impact force histories, a rotational spring is used at the edges

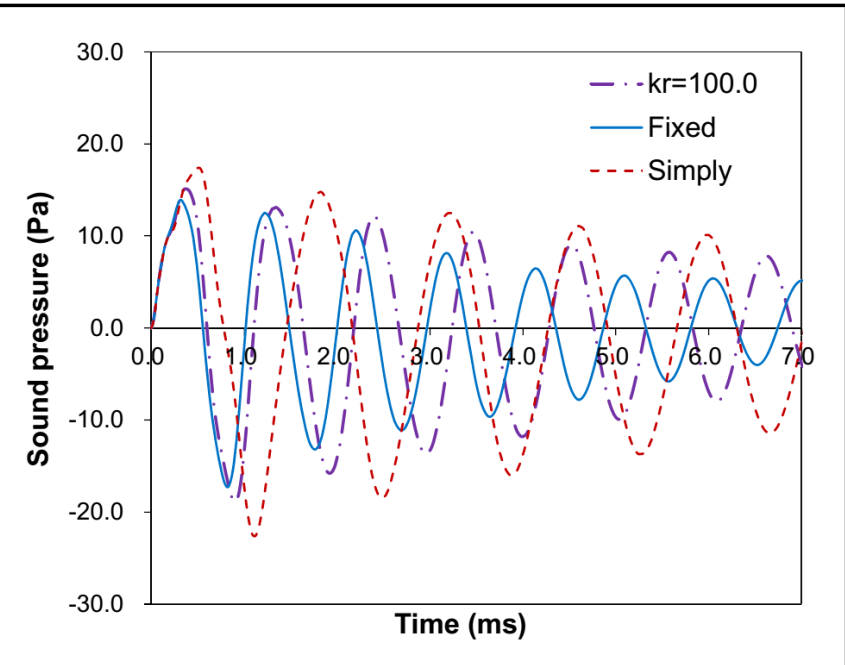

Figure 14. Comparison of sound pressure history with rotational stiffness $100.0 \mathrm{Nm}$.

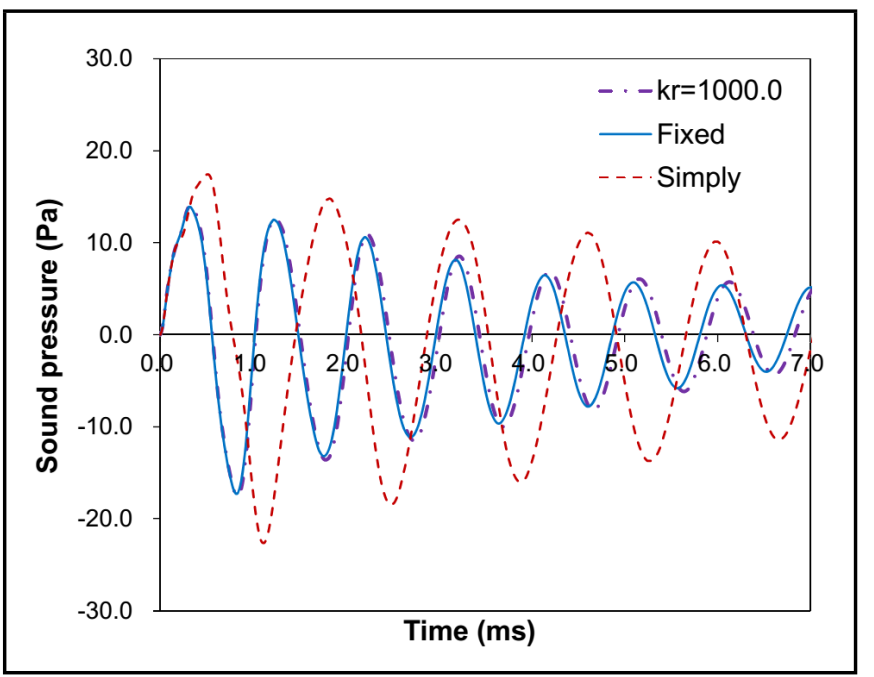

Figure 15. Comparison of sound pressure history with rotational stiffness $1000.0 \mathrm{Nm}$.

of the plate. Figure 7 shows the elastically supported boundary condition used for the impact response and acoustic sound analysis. Figures 8-11 show the impact force histories of a rotationally supported plate when the rotational stiffness was $1.0 \mathrm{Nm}, 10.0 \mathrm{Nm}, 100.0 \mathrm{Nm}$, and $1000.0 \mathrm{Nm}$, respectively. The plate had dimensions of $19 \times 19 \mathrm{~cm}^{2}$ and the laminate had a lay-up $[0 / 45 / 0 /-45 / 0 /-45 / 0 / 45 / 90]_{s}$. The motion of the four edges was assumed to be restrained by a rotational spring, $k_{r}$. It can be noted from these figures that the maximum contact force increased and the contact duration decreased as the rotational stiffness increased. In this case, the impact velocity is $0.337 \mathrm{~m} / \mathrm{s}$ and the equivalent mass is $0.956 \mathrm{~kg}$. Figures $12-15$ show the sound pressure histories of the rotationally supported plate when the rotational stiffness was $1.0 \mathrm{Nm}, 10.0 \mathrm{Nm}, 100.0 \mathrm{Nm}$, and $1000.0 \mathrm{Nm}$, respectively. The sound pressure was calculated at $15.0 \mathrm{~cm}$ above the centre of the plate. To investigate the effect of the rotational stiffness in a frequency domain, a comparison of spectra is shown in Figs. 16-19. These were achieved by carrying out a Fourier transform of the sound pressure histories. From the results, it is known that the contents of frequency increased as the rotational stiffness increased. 


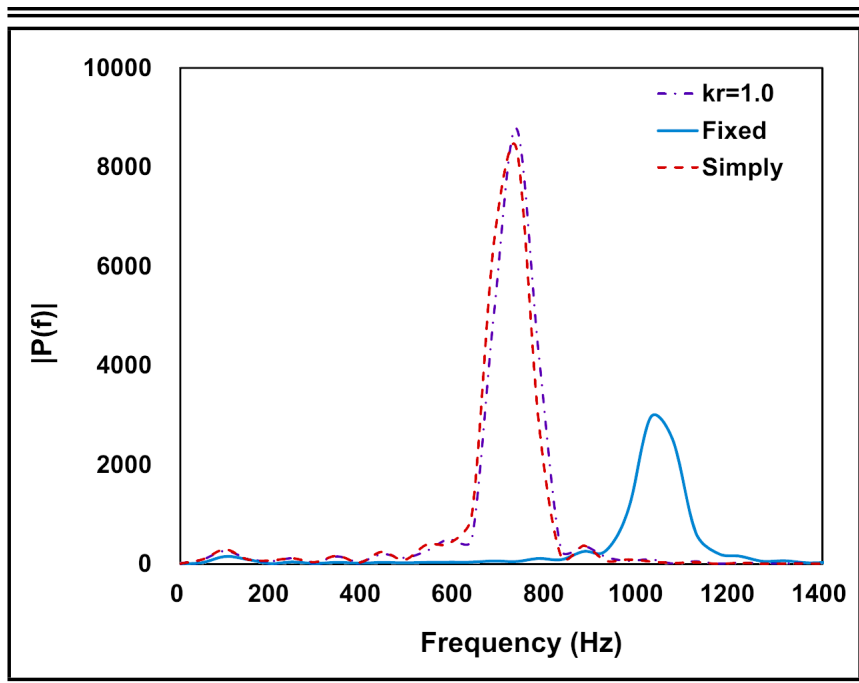

Figure 16. Comparison of spectra of sound pressure history with rotational stiffness $1.0 \mathrm{Nm}$.

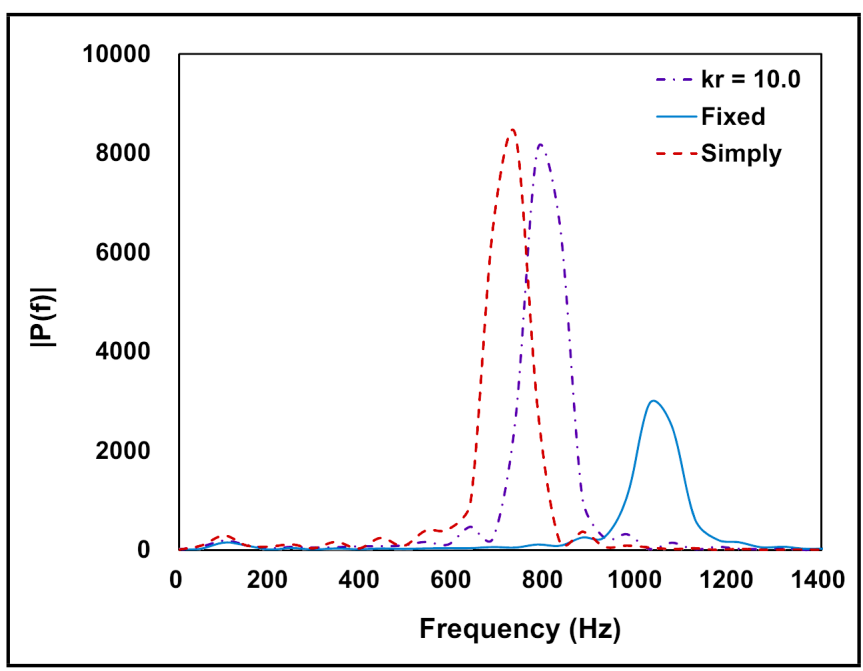

Figure 17. Comparison of spectra of sound pressure history with rotational stiffness $10.0 \mathrm{Nm}$.

\subsection{Damage Detection in Sandwich Structure}

Figure 20 shows a spring mass model of a sandwich structure. In this model, a sandwich plate was constructed as an assembly of a face modelled with four-node plate elements and a core modelled with eight-node solid elements. ${ }^{16}$ Figure 21 shows the debonding model of the sandwich plate. The nodes of the debonding area are detached and not connected to each other when the sandwich structure is impacted by the lumped mass. The analysis model of the sandwich plate is $19 \times 19 \times 1.5 \mathrm{~cm}^{3}$, and the boundary condition of the plate is four edges clamped. The face of the sandwich plate has a lay-up of $[0 / 45 /-45 / 0]_{\mathrm{s}}$, and the size of debonding is $0.3 \times 0.3 \mathrm{~cm}^{2}$. Figure 22 shows the comparison of the impact force histories of undamaged and debonded sandwich plates. In this case, the impact velocity is $0.337 \mathrm{~m} / \mathrm{s}$ and the equivalent mass of the impactor is $0.092 \mathrm{~kg}$. It can be observed from the result that the maximum contact force decreased and the contact duration increased due to debonding. A comparison of sound pressure histories computed by analysis both with and without debonding is shown in Fig. 23. The sound pressure was calculated at $15.0 \mathrm{~cm}$ above the centre of the plate, and

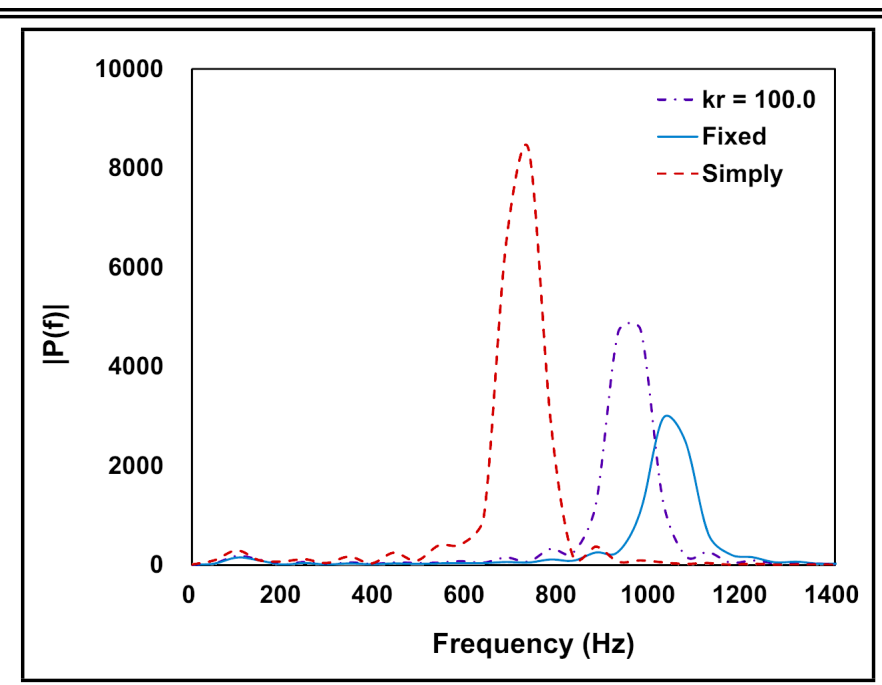

Figure 18. Comparison of spectra of sound pressure history with rotational stiffness $100.0 \mathrm{Nm}$.

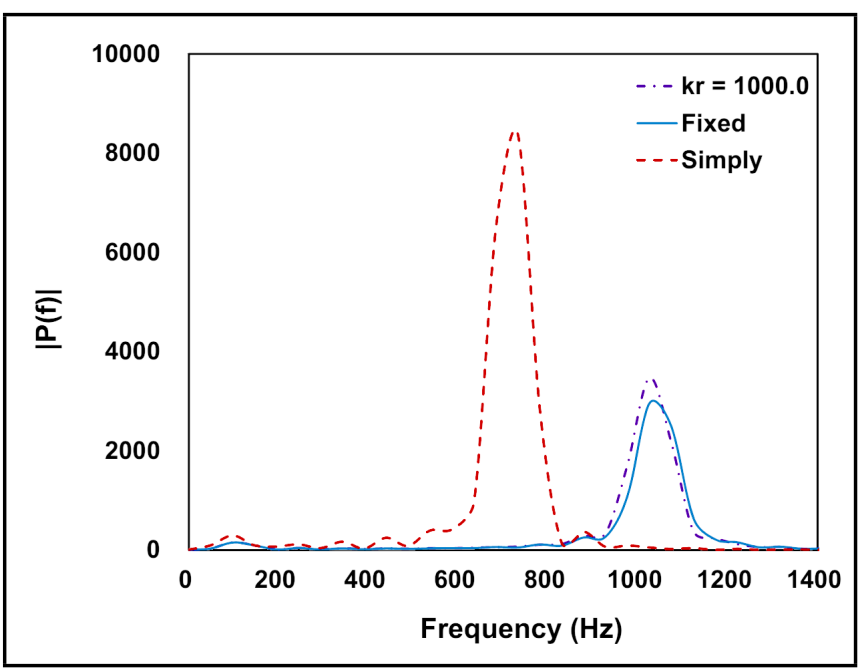

Figure 19. Comparison of spectra of sound pressure history with rotational stiffness $1000.0 \mathrm{Nm}$.

Fig. 24 shows the spectra of the sound pressure history. From the results, it is observed that the impact on the damaged area did not excite the higher structural modes as strongly as the impact on the undamaged area. Therefore, the sound produced does not contain higher frequencies and the structure sound is "duller".

\subsection{Application of Tap Test to Rotor Blade}

Figure 25 shows the FE model of composite rotor blade. The span length is $9.45 \mathrm{~m}$, cord length is $0.46 \mathrm{~m}$ and crack length is $0.15 \mathrm{~m}$. In this model, four-node plate element was used. The total number of elements are 51,644 and nodes are 50,614. The laminate had a lay-up $[0 / 45 / 0 /-45 / 0 /-45 / 0 / 45 / 90]_{2 s}$. The fixed boundary condition is applied to root of rotor blade. Figure 26 shows the comparison of the impact force histories of undamaged and cracked models. In this case, the impact velocity is $0.337 \mathrm{~m} / \mathrm{s}$ and the equivalent mass of the impactor is $0.956 \mathrm{~kg}$. It can be observed from the result that the maximum contact force decreased and the contact duration increased due to crack. 


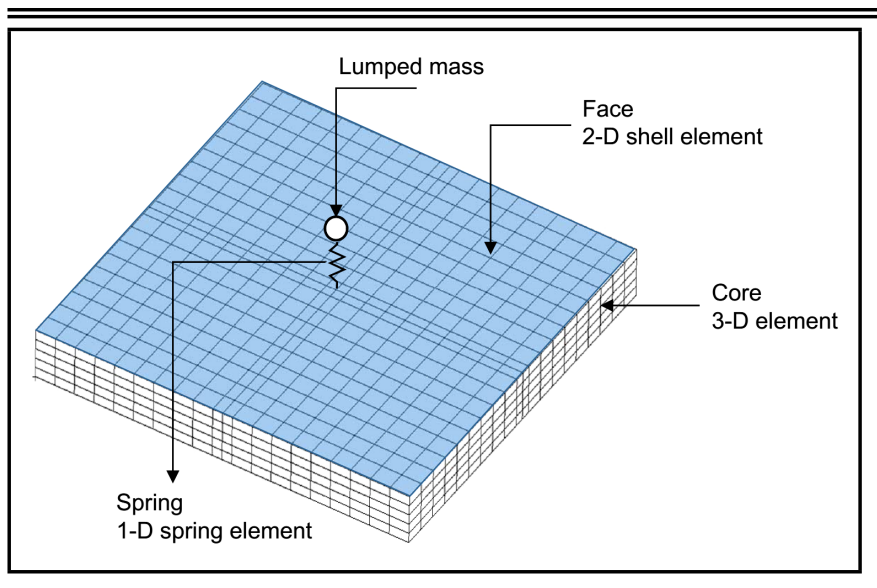

Figure 20. Spring mass model of sandwich plate for impact analysis.

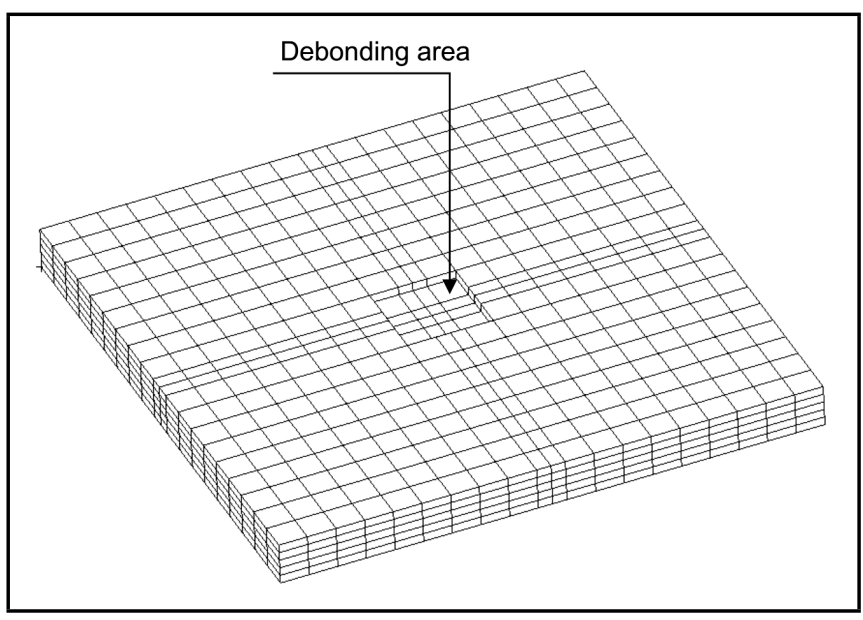

Figure 21. Debonding model of sandwich plate.

\section{CONCLUSION}

The purpose of this study was to investigate the physical basis of tapping sound. In this paper, the elastically restrained composite laminates were modelled by a spring element, and the effects of a rotational stiffness were reviewed. It can be noted from the results that the maximum contact force increased and the contact duration decreased as the rotational stiffness increased. The frequency contents of sound pressure increased as the rotational stiffness increased. The spring mass model was also used to simulate a tap test on a sandwich structure, and the effects of disbond in the sandwich structure was numerically investigated. The numerical results show that there is a strong correlation between the debonding and reduction in impact force and the contents of high-frequency sound pressure. From the impact response analysis on composite rotor blade, it is observed that this numerical model can be applied to real structure. The results presented above show that it is possible to detect damage in a composite structure using an impact force or sound pressure by comparing either the time history or the corresponding spectrum with signals from a structure.

\section{ACKNOWLEDGEMENTS}

This study was supported by the 'Study on the light structure and structural integrity improvement technology' program funded by the National Research Council of Science \& Technology, Republic of Korea.

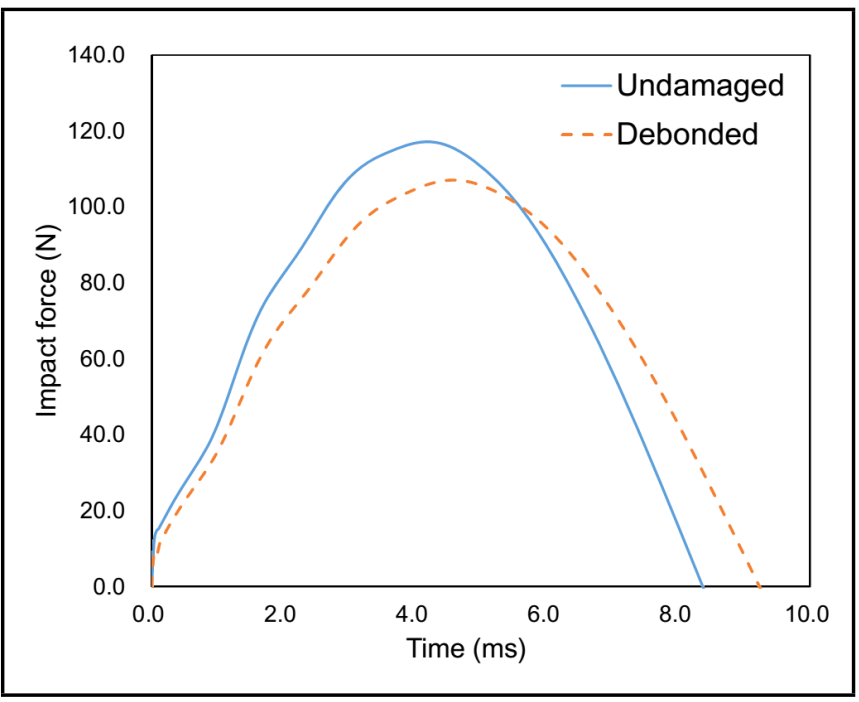

Figure 22. Comparison of impact force history between undamaged and debonded sandwich plate.

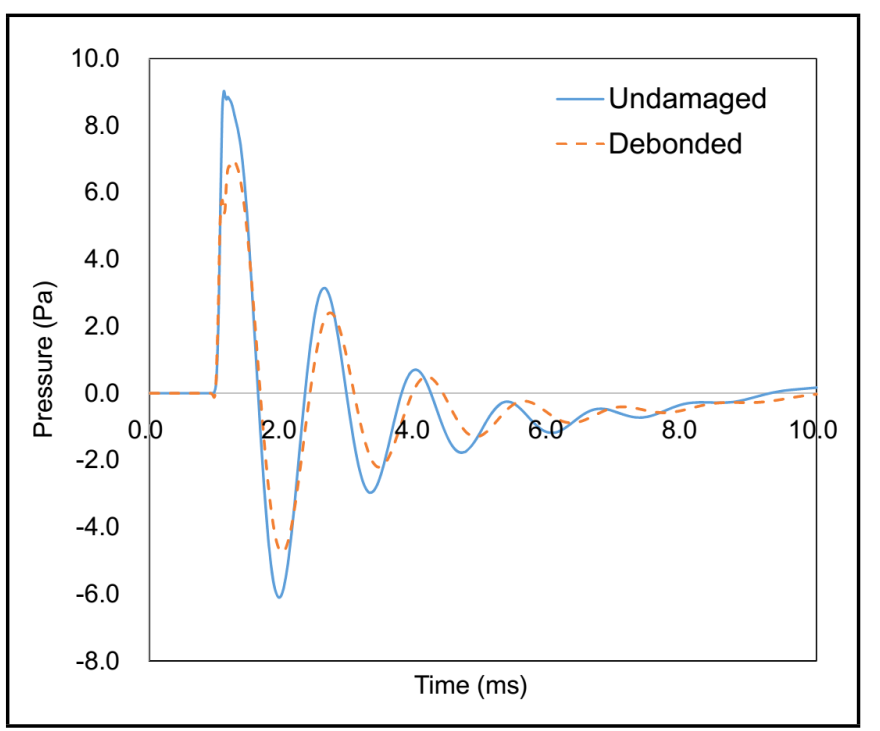

Figure 23. Comparison of sound pressure history between undamaged and debonded sandwich plate.

\section{REFERENCES}

1 Gagne, M. and Therriault, M. Lightning strike protection of composites, Progress in Aerospace Sciences, 64, 1-16, (2014). https://dx.doi.org/10.1016/j.paerosci.2013.07.002

2 Katnam, K. B., Da Silva, L. F. M., and Young, T. M. Bonded repair of composite aircraft structures: A review of scientific challenges and opportunities, Progress in Aerospace Sciences, 61, 26-42, (2013). https://dx.doi.org/10.1016/j.paerosci.2013.03.003

3 Rehman, S., Ibrahim, Z., Memon, S., and Jameel, M., Nondestructive test methods for concrete bridges: A review, Construction and Building Materials, 107, 58-86, (2015). https://dx.doi.org/10.1016/j.conbuildmat.2015.12.011

4 Yang, R., He, Y., and Zhang, H., Progress and trends in nondestructive testing and evaluation for wind turbine composite blade, Renewable and Sustainable Energy Reviews, 60, 1225-1250, (2016). https://dx.doi.org/10.1016/j.rser.2016.02.026 


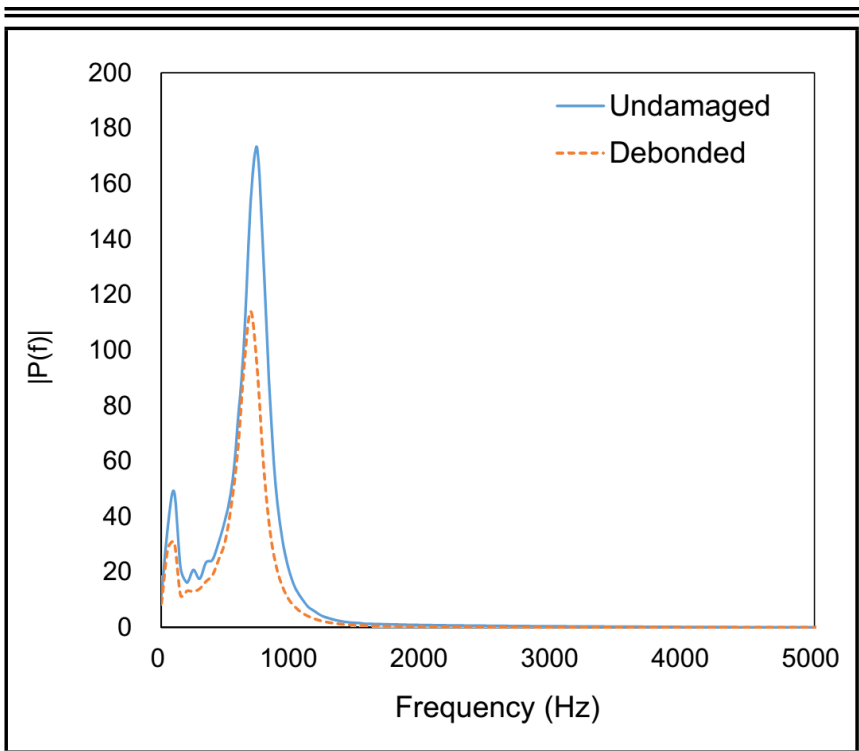

Figure 24. Comparison of spectra of sound between undamaged and debonded sandwich plate.

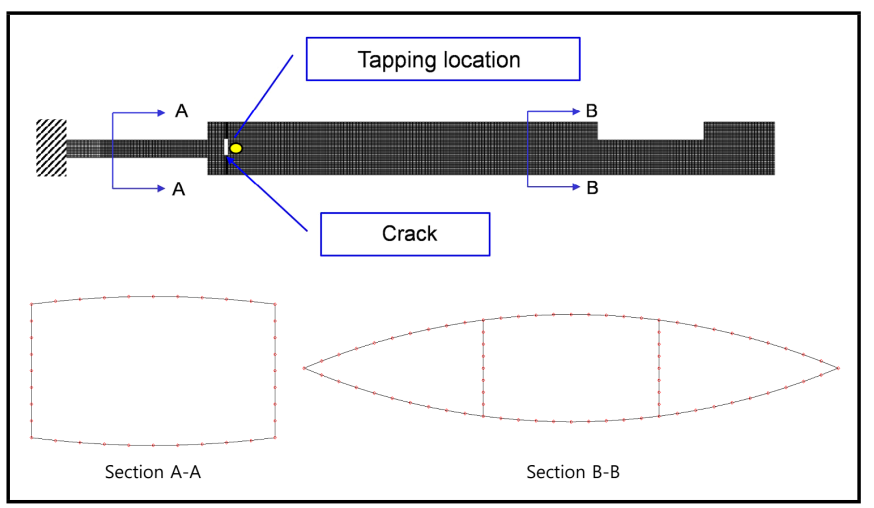

Figure 25. Finite element model of composite rotor blade.

5 Ibrahim, M. E. Nondestructive evaluation of thick-section composites and sandwich structures: A review, Composites Part A: Applied Science and Manufacturing, 64, 36-48, (2014). https://dx.doi.org/10.1016/j.compositesa.2014.04.010

6 Cawley, P., and Adams, R. D. The mechanics of the coin-tap method of non-destructive testing, Journal of Sound and Vibration, 122, 299-316, (1988). https://dx.doi.org/10.1016/s0022-460x(88)80356-0

7 Shivakumar, K. N. and Elber, W. Prediction of impact force and duration due to low-velocity impact on circular composite laminates, ASME Journal of Applied Mechanics, 52, 674-680, (1985). https://dx.doi.org/10.1115/1.3169120

8 Choi, I. H. and Lim, C. H. Low-velocity impact analysis of composite laminates using linearized contact law, Composite Structures, 66, 125-132, (2004). https://dx.doi.org/j.compstruct.2004.04.030

9 Choi, I. H. Contact force analysis of composite sandwich plates subjected to low-velocity impact, Composite Structure, 75, 582-586, (2006). https://dx.doi.org/j.compstruct.2006.04.017

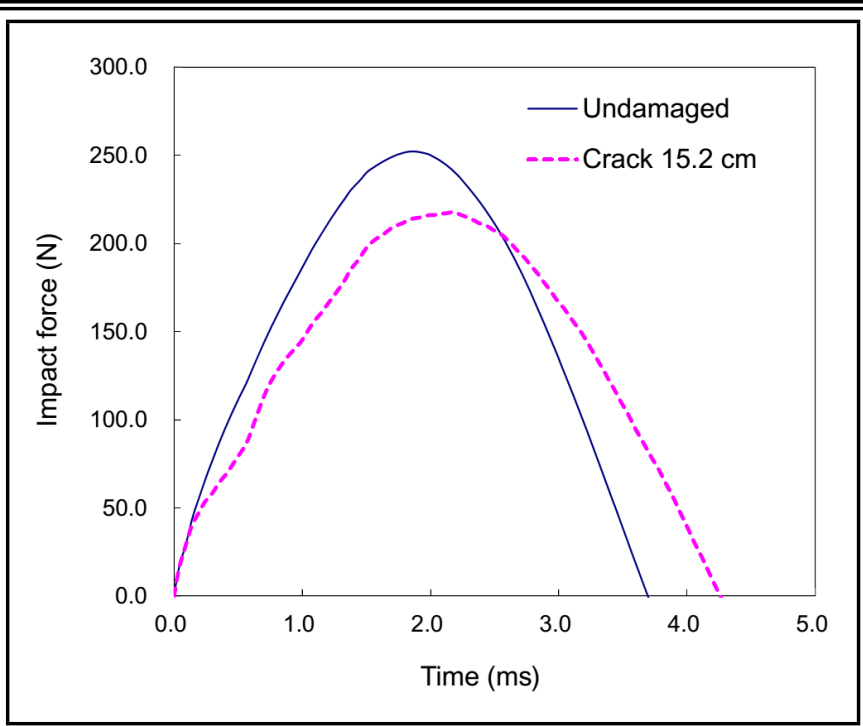

Figure 26. Comparison of impact force histories for cracked and undamaged model of rotor blades.

10 Kim, S. J. Damage detection in composite under in-plane load using tap test, Journal of Mechanical Science and Technology, 29, 199-207, (2015). https://dx.doi.org/10.1007/s12206-014-1103-5

11 Mehraby, K., Khademhosseini Beheshti, H., and Poursina, M. Impact noise radiated by collision of two spheres: Comparison between numerical simulations, experiments and analytical results, Journal of Mechanical Science and Technology, 25 (7), 1675-1685, (2011). https://dx.doi.org/10.1007/s12206-011-0503-z

12 Schedin, S., Lambourge, C., and Chaigne, A. Transient sound fields from impacted plates: comparison between numerical simulations and experiments, Journal of Sound and Vibration, 221 (3), 471-490, (1999). https://dx.doi.org/10.1006/jsvi.1998.2004

13 Minak, G. and Ghelli, D. Influence of diameter and boundary conditions on low velocity impact response of CFRP circular laminated plates, Composites Part B: Engineering, 39, 962-972, (2008). https://dx.doi.org/10.1016/j.compositesb.2008.01.001

14 Hoo, M. S., Fatt, M. S., and Park, K. S. Dynamic models for low-velocity impact damage of composite sandwich panels-Part A: Deformation, Composite Structure, 52, 335-351, (2001). https://dx.doi.org/10.1016/s02638223(01)00026-5

15 Akay, A. and Latcha, M. Sound radiation from an impactexcited clamped circular plate in an infinite baffle, Journal of the acoustical society of America, 74 (2), 640-648, (1983). https://dx.doi.org/10.1121/1.389787

16 Kim, S. J. and Kim, T. Damage detection in sandwich structure using tap test, Proceedings of INTER-NOISE 2016, Hamburg, Germany, 4299-4303, (2016). 